\title{
Editorial
}

\section{Time to agree guidelines and apply an ethical framework for public health nutrition}

In this issue of the journal, Arne Oshaug is asking what the food industry is doing in nutrition conferences ${ }^{(1)}$. The purpose of his commentary is to start a new discussion about the relationship of the food, drinks and associated industries with the organisers of nutrition science conferences. We support this call and commend Arne Oshaug for taking on this challenging issue. The key message from the commentary is that without greater accountability and transparency in the relationships between the nutrition community and the wider food and drink industry, we will (rightly) lose credibility as the professional voice that champions public health nutrition. Guidelines need to be agreed, and compliance with these monitored. It is clear that to date we have not operated conferences according to these principles. We believe we can run meetings and conferences in a different way that is less reliant on industry sponsorship and that where sponsorship exists it is open and clear for all to see. Funders should not dictate who speaks and what they say.

Guidelines have also been agreed for journal publishing $^{(2)}$. Guidelines have been established in some countries around disclosure of competing interests for people sitting on government or other advisory bodies ${ }^{(3)}$. In the UK, the Committee on Standards in Public Life has articulated seven principles of public life: selflessness; integrity; objectivity; accountability; openness; honesty; and leadership. What is meant by each of these has been expanded upon. Although originally articulated for members of Parliament, they are now applied to all those who work for government including those who sit on advisory boards or committees.

Guidelines as to how we operate such an ethical framework for all aspects of our professional work need to be agreed and adhered to. If we want to be taken seriously as a profession, we must agree and follow these principles and be prepared to be open about deviation from best practice. These guidelines should be applied to the way individuals, societies and professional bodies, funders, government, international agencies, nongovernment organisations (NGOs) and business-interest NGOs (BINGOs) operate.

At the moment the wider community can obtain information about nutrition and health from many different sources, freely available on the Internet. It is not easy to establish, unless you dig very deep (and even then it may not be possible), who funds the work and whether the information is reliable. Part of the framework should involve a kite mark of agreed standards of best practice for such web-based sources.

Among professional groups in nutrition, we need to follow an agreed ethical framework from which information can be derived that allows the wider community to judge whether the work we do and the views we express are biased by the source of funding we receive, in terms of our salary, grants or other in-kind support. The key elements of the guidance probably centre on openness and transparency, although all seven principles are important. At the moment much of what happens in nutrition is not open and transparent. We need greater accountability and transparency in how researchers, universities and professional societies obtain funds from the food, drinks and associated industries, and how the source of funding directly or indirectly may be thought to influence what work is undertaken and the way the findings of such work are communicated. There is a need for greater clarity and transparency in the way BINGOs are funded and how they influence policy making.

We are not saying this will be easy or always practical, but we must do better than we currently are if we want to be taken seriously as a profession. Some may ask, where does this declaration stop, should we find out and declare where our colleagues and schools and faculties receive their funds and write a ten-page report documenting this every time we speak or write? We need guidelines that allow others to judge whether what we say and do is in some way biased by the funding we receive. Government and international agency funders may put as much pressure on researchers to control what they say as funders from the food and drinks industry. Acknowledging that we may all be biased or prejudiced in some ways is important.

This is challenging, and we are not against appropriate links with industry. Until we start behaving professionally, all who work in nutrition will be tarred with the brush of those who exploit their position for personal gain. We are not opposed to working with funders from different sources; we just want this to operate in a more open and transparent way, so readers and listeners can make an informed judgement as to whether what we are saying and doing is biased by the source of funding of our work. 
We need to agree urgently on this wider set of guidelines. We believe we should use the next International Congress on Nutrition, to be held in a few months in Bangkok, as the platform to seriously launch a process on the rapid agreement of these guidelines. If our professional associations and institutions do not support this initiative we need to know why. We must take up the challenge that Arne Oshaug places before us.

\section{References}

1. Oshaug A (2009) What is the food and drink industry doing in nutrition conferences? (Invited commentary). Public Health Nutr 12, 1019-1020.

2. Margetts B, Finlay D, Monteiro C, Oniang'o R \& Shetty P (2008) International Union of Nutritional Sciences review of publishing Ethics: Recommendations. http://www.iuns. org/features/IUNS\%20working\%20group\%20on\%20publishing \%20ethics-0608.pdf (accessed February 2009).

3. Committee on Standards in Public Life (1996) Summary of the Nolan Committee's First Report on Standards in Public Life. http://www.archive.official-documents.co.uk/ document/parlment/nolan/nolan.htm (accessed May 2009).
Barrie Margetts

Deputy Editor 